\title{
Penetration of Drug Resistance in Escherichia coli Isolated from Laboratory Animals
}

\author{
Kouji SHIMODA ${ }^{1)}$, Jun KIMURA ${ }^{1)}$, Satoshi OGURI ${ }^{1)}$, Naoko NAKAMURA ${ }^{2)}$, Toru URANO ${ }^{2)}$ and \\ Kazuyoshi MAEJIMA ${ }^{1)}$ \\ ${ }^{1)}$ Laboratory Animal Center, Keio University School of Medicine, 35 Shinanomachi, Shinjuku-ku, Tokyo 160-8582 and ${ }^{2)}$ Division of \\ Microbiology and Genetics, Center for Animal Resources and Development, Kumamoto University, 2-2-1 Honjo, Kumamoto 860-0811, \\ Japan
}

(Received 23 May 2002/Accepted 7 August 2002)

ABSTRACT. A total of 713 strains of fecal Escherichia coli (E. coli) isolated from laboratory animals in the colonies of 4 research laboratories and 4 commercial breeders in Japan in 1994 were examined in regard to resistance to 8 antibacterial agents. The incidence of resistance to sulfadimethoxine $(\mathrm{Su})$, streptomycin $(\mathrm{Sm})$, ampicillin, cephaloridine, tetracycline, chloramphenicol, kanamycin, and gentamicin was $99.9 \%, 32.5 \%, 6.7 \%, 0.7 \%, 7.0 \%, 2.6 \%, 6.6 \%$ and $0.7 \%$, respectively. These results indicated that Su and Sm resistance are penetrating into normal $E$. coli strains isolated from laboratory animals.

KEY WORDS: drug resistance, Escherichia coli, laboratory animal.

It is well recognized that the administration of antibiotics to animals for any purpose (growth promotion, prophylaxis, or therapy) leads to accumulation of resistant bacteria in their flora [3]. The large number of drug-resistant organisms in livestock and poultry have been suspected of being a source of resistance in humans and other animals [5]. The incidence of drug-resistant Escherichia coli (E. coli) in laboratory animals has been very low because of the principle of avoiding the use of antibiotics in research animals $[6,13]$. Nevertheless, a high incidence of drug resistance has been observed in a few laboratory animal colonies in which antibiotic agents were routinely administered to prevent infectious diseases $[11,12]$. In this study we used the same protocol as in the former investigation in the 1980s to survey the drug resistance of normal E. coli strains isolated from laboratory animals [12].

A total of $713 \mathrm{E}$. coli strains were isolated from fecal samples obtained from laboratory animals (70 mice, 70 rats, 10 guinea pigs, and 20 rabbits) in the colonies of 4 research laboratories and 4 commercial breeders in 1994. As a rule, about 5 E. coli strains were collected from each animal. The animal colonies investigated were from representative laboratories or breeders located on Kyushu Island in Japan. Application of antibacterial agents was evident in mouse colonies A (cefotiam), C (tetracycline and fradiomycin) and $\mathrm{E}$ (itraconazole), and a rabbit colony $\mathrm{C}$ (sulfa drug). The $E$. coli strains were isolated on deoxycholate-hydrogen sulfidelactose agar (DHL, Eiken Chemical Co., Ltd.) plates, and identified biochemically and morphologically.

Drug resistance was determined as bacterial growth on agar plates containing $25 \mu \mathrm{g}$ of ampicillin (Ap), cephaloridine (Cer), tetracycline (Tc), kanamycin ( $\mathrm{Km})$, chloramphenicol $(\mathrm{Cp})$ or gentamycin $(\mathrm{Gm})$ per $\mathrm{ml}, 12.5 \mu \mathrm{g}$ of streptomycin $(\mathrm{Sm})$ per $\mathrm{ml}$, or $100 \mu \mathrm{g}$ of sulfadimethoxine $\mathrm{Su})$ per $\mathrm{ml}$. The concentrations of these antibiotics were determined in our previous study [12] and were applied in this survey for comparison with the previous results pub- lished in this journal.

The incidence of drug-resistant $E$. coli is shown in Table 1. Su resistance was detected in 712 of the 713 isolates examined. The incidence of Su resistance in laboratory animals was comparable to that in domestic animals in which no susceptibility to Su was detected in over $90 \%$ of normal E. coli isolates, although the bimodal distribution of the minimal inhibitory concentration of $\mathrm{Su}$ was not apparent with the antibiotic disk diffusion method [15]. Hausen and Velschow reported that $60 \%$ of $E$. coli strains isolated from laboratory animals in Denmark were resistant to sulfonamides $(240 \mu \mathrm{g})$ [4]. Our previous survey in the $1980 \mathrm{~s}$ showed that only a few percent of $E$. coli isolates exhibited resistance to $\mathrm{Su}$ under the same conditions as in this study [12].

Sm resistance was frequently observed in $E$. coli strains isolated from laboratory animals, with 232 (32.5\%) of the 713 strains showing resistance, and thus $\mathrm{Sm}$ resistance seemed to be penetrating E. coli strains in laboratory animals. Resistance to Ap, Cer, Tc, $\mathrm{Cp}, \mathrm{Km}$ and $\mathrm{Gm}$ was detected in $6.7 \%, 0.7 \%, 7.0 \%, 2.6 \%, 6.6 \%$ and $0.7 \%$, respectively, of the strains. The incidence of Tc resistance in this study was comparable to its incidence in our previous survey [12], whereas the Tc resistance of E. coli strains was most common (50\%) in livestock and poultry [15].

The patterns of resistance of $E$. coli strains to drugs other than Su in individual colonies are shown in Table 2. Multiple resistance to 6 drugs was detected in mouse isolates in colony $\mathrm{C}$, which was from a conventional animal facility with a history of Tc administration to mice in drinking water. This multiple resistance was transferable to other $E$. coli strains via $\mathrm{R}$ plasmids during mixed cultivation (data not shown). In other colonies, most resistant strains exhibited resistance to $\mathrm{Sm}$ alone, and few isolates showed double or triple resistance to $\mathrm{Sm}$ and other drugs. Many resistant organisms were detectable in colonies B, D, F, G and $\mathrm{H}$, which were obtained from animals with no history of treat- 
Table 1. Incidence of $E$. coli resistant to individual drugs

\begin{tabular}{lccccc}
\hline Animal & Mouse & Rat & $\begin{array}{c}\text { Guinea } \\
\text { pig }\end{array}$ & Rabbit & Total (\%) \\
\hline $\begin{array}{l}\text { No. of E. coli } \\
\text { tested }\end{array}$ & 302 & 316 & 25 & 70 & 713 \\
\hline $\begin{array}{l}\text { No. of E. coli } \\
\text { resistant to }\end{array}$ & & & & & \\
Su & 301 & 316 & 25 & 70 & $712(99.9)$ \\
Sm & 140 & 72 & 3 & 17 & $232(32.5)$ \\
Ap & 22 & 3 & 12 & 11 & $48(6.7)$ \\
Cer & 5 & 0 & 0 & 0 & $5(0.7)$ \\
Tc & 45 & 0 & 0 & 5 & $50(7.0)$ \\
Cp & 19 & 0 & 0 & 0 & $19(2.6)$ \\
Km & 47 & 0 & 0 & 0 & $47(6.6)$ \\
Gm & 5 & 0 & 0 & 0 & $5(0.7)$ \\
\hline
\end{tabular}

Table 2. Patterns of resistance to drugs except Su in individual colonies

\begin{tabular}{|c|c|c|c|c|}
\hline Animal & Colony & $\begin{array}{l}\text { No. of } E \text {. coli } \\
\text { isolated }\end{array}$ & $\begin{array}{l}\text { No. of E. coli } \\
\text { resistant }(\%)\end{array}$ & $\begin{array}{l}\text { Resistance pattern } \\
\text { (No. of strains) }\end{array}$ \\
\hline \multirow[t]{17}{*}{ Mouse } & A & 50 & $30(60)$ & $\operatorname{Sm}(30)$ \\
\hline & B-1 & 40 & $18(45)$ & Sm (15) \\
\hline & & & & Ap (2) \\
\hline & & & & Sm-Ap (1) \\
\hline & B-2 & 49 & $23(47)$ & Sm-Km (6) \\
\hline & & & & Sm (17) \\
\hline & $\mathrm{C}$ & 47 & $45(96)$ & Sm-Tc-Km-Cp-Ap-Cer (5) \\
\hline & & & & Sm-Tc-Km-Cp-Ap (3) \\
\hline & & & & Sm-Tc-Km-Cp (11) \\
\hline & & & & Sm-Tc-Km-Ap (1) \\
\hline & & & & Sm-Tc-Km (15) \\
\hline & & & & Sm-Tc-Ap (10) \\
\hline & E & 20 & $1(5)$ & $\operatorname{Sm}(1)$ \\
\hline & $\mathrm{F}$ & 50 & $0(0)$ & - \\
\hline & $\mathrm{H}$ & 46 & $25(54)$ & Sm-Km-Gm (5) \\
\hline & & & & Sm-Km (1) \\
\hline & & & & $\operatorname{Sm}(19)$ \\
\hline \multirow[t]{7}{*}{ Rat } & A & 50 & $12(24)$ & $\operatorname{Sm}(12)$ \\
\hline & B-3 & 50 & $8(16)$ & Sm (8) \\
\hline & $\mathrm{D}$ & 85 & $11(13)$ & $\operatorname{Sm}(11)$ \\
\hline & $\mathrm{E}$ & 32 & $0(0)$ & - \\
\hline & $\mathrm{F}$ & 49 & $16(33)$ & Sm-Ap (3) \\
\hline & & & & Sm (13) \\
\hline & $\mathrm{H}$ & 50 & $25(50)$ & $\operatorname{Sm}(25)$ \\
\hline \multirow{3}{*}{$\begin{array}{l}\text { Guinea } \\
\text { pig }\end{array}$} & A & 17 & $12(71)$ & Ap 12 \\
\hline & B-3 & 3 & $0(0)$ & - \\
\hline & $\mathrm{C}$ & 5 & $3(60)$ & Sm (3) \\
\hline \multirow[t]{6}{*}{ Rabbit } & A & 13 & $11(85)$ & Sm-Ap (2) \\
\hline & & & & Ap (9) \\
\hline & B-3 & 28 & $5(18)$ & Sm (5) \\
\hline & $\mathrm{C}$ & 18 & $10(56)$ & Sm-Tc (5) \\
\hline & & & & Sm (5) \\
\hline & G & 11 & $0(0)$ & - \\
\hline
\end{tabular}

ment with antibiotics. No resistant organisms were observed in mouse colony $\mathrm{F}$, rat colony $\mathrm{E}$, guinea pig colony $\mathrm{B}$ or rabbit colony $\mathrm{G}$, which also had no history of antibiotic treatment.

Hausen and Velschow reported a high incidence of drug- resistant E. coli in European laboratory animal colonies never treated with antibiotics [4], and the incidence of Smresistant E. coli was higher than in our study. These findings indicate that penetration of drug-resistant organisms might be proceeding in laboratory animals in both Europe 
and Japan. Hausen and Velschow also stated that the drug resistances in laboratory animals could not have resulted in direct immigration of drug-resistant E. coli strains in humans and domestic animals because of the differences between them in the resistance pattern. Our results also indicated that the Tc resistance of $E$. coli isolates, which was most frequently observed in domestic animals [15], was not prevalent in laboratory animals. Indeed the intestinal bacterial flora usually tended to reject resistant bacterial strains that newly immigrated into the digestive tract without any selective pressure of antibiotic administration [8-10].

The detection of Su resistance in all strains but one from laboratory animals in Japan in 1994 was surprising, because our previous study showed that only a few percent of the $E$. coli isolates in the 1980s had been able to grow on agar plates containing $\mathrm{Su}$ at the same concentration as in this study [12]. It was anticipated that environmental contamination by $\mathrm{Su}$ and/or other antibiotics below the practical detection level might influence the bacterial population after a long latent period $[2,7,14]$. Broad surveillance of drugresistant organisms is crucial to assessment of the risk of antibiotic-resistant bacteria to public health [1]. Periodic investigation of the epidemiology of antibiotic-resistant organisms is necessary for proper management to reduce the threat of bacterial disease in humans and animals.

\section{REFERENCES}

1. Anderson, R. M. 1999. Nature Med. 5: 147-149.
2. Boon, P. I. and Cattanach, M. 1999. Lett. Appl. Microbiol. 28: 164-168.

3. Dupont, H. L. and Steele, J. H. 1987. Rev. Infect. Dis. 9: 447460.

4. Hausen, A. K. and Velschow, S. 2000. Lab. Anim. 34: 413422.

5. Kruse, H. and Sorum, H. 1994. Appl. Environ. Microbiol. 60: 4015-4021.

6. Maejima, K., Urano, T., Tamura, H. and Terakado, N. 1980. Exp. Anim. (Tokyo) 29: 71-75.

7. Moro, M. H., Beran, G. W., Hoffman, L. J. and Griffith, R. W. 1998. Lett. Appl. Microbiol. 27: 251-254.

8. Shimoda, K., Kuhara, T. and Maejima, K. 1991. Exp. Anim. (Tokyo) 40: 425-430.

9. Shimoda, K., Maejima, K., Sekizaki, T. and Terakado, N. 1984. Jpn. J. Vet. Sci. 46: 181-187.

10. Shimoda, K., Maejima, K. and Terakado, N. 1985. Jpn. J. Vet. Sci. 47: 669-672.

11. Shimoda, K., Maejima, K. and Urano, T. 1984. Exp. Anim. (Tokyo) 33: 351-355.

12. Shimoda, K., Maejima, K., Urano, T. and Terakado, N. 1983. Jpn. J. Vet. Sci. 45: 103-108.

13. Sundara, P. and Kashiwazaki, M. 1973. Exp. Anim. (Tokyo) 22: $1-4$.

14. Tsubokura, M., Matsumoto, A., Otsuki, K., Animas, S. B. and Sanekata, T. 1995. J. Wildlife Dis. 31: 352-357.

15. The Report of Japanese Veterinary Antimicrobial Resistance Monitoring System. 2002. http://www.nval.go.jp/taisei/ 12taisei/12sei.htm 